\title{
Bioefficacy of plant extracts on stem rot, Macrophomina phaseolina (Tassi) Goid and Bihar hairy caterpillar, Spilosoma obliqua Walker in jute crop
}

\author{
H. Chowdhury, B. S. Gotyal*, K. Selvaraj and S. K. Sarkar \\ Central Research Institute for Jute and Allied Fibres, Barrackpore, Kolkata-700120, INDIA \\ *Corresponding author. E-mail: gotyalento@gmail.com \\ Received: May 28, 2015; Revised received: September 18, 2015; Accepted: February 11, 2016
}

\begin{abstract}
In vitro study was conducted to test mycellial growth inhibition effect of plant extracts on Macrophomina phaseolina causing stem rot of jute as well as for feeding inhibition and mortality on $3^{\text {rd }}$ instar larvae of Bihar hairy caterpillar, Spilosoma obliqua Walker. The result revealed, at $2000 \mathrm{ppm}$, acetone extracts of sunnhemp and Azeratum conyzoides exhibited maximum of $34.44 \%$ and $41.85 \%$ mycellial growth inhibition respectively. Whereas, $83.32 \%$ and $66.67 \%$ spore germination inhibition of the fungus was observed respectively. At 5000 ppm, methanolic extracts of Crotolaria quinquefolia, garlic, curry leaf and turmeric oil recorded $35.55 \%, 44.44 \%, 50.00 \%$ and $70.00 \%$ mycellial growth inhibition of the fungus. Methanolic extracts of $C$. juncea, $C$. quinquefolia, curry leaf and garlic recorded above $80.00 \%$ feeding inhibition on S. obliqua and larval mortality of $20.00 \%-44.44 \%$. It is clear that neem, sunnhemp, garlic and turmeric extract possess antifungal, insecticidal, antifeedant properties and may be integrated for management of stem rot as well as $S$. obliqua in jute crop.
\end{abstract}

Keywords: Feeding inhibition, Larval mortality, Macrophomina phaseolina, Plant extracts, Spilosoma obliqua, Spore germination

\section{INTRODUCTION}

Indiscriminate use of synthetic pesticides to ensure higher crop yield have adversely affected both biological and physical environment, leading to the pollution of biosphere and rapid build-up of resistance and resurgence of insect pests and diseases (Chowdhury et al., 2012b). The damage is caused due to high toxicity and non-biodegradable nature of the pesticides and due to the residues in soil, water and crops that affect human health. Thus, efforts are needed to search new selective and biodegradable pesticides. In the move towards green pesticides and the continuing need for developing new crop protection tools, phytochemicals derived from various bio-active plant species offer a promising source of safer agrochemicals (Isman, 2006). There are many botanical products that have been reported as antifungal compounds (Chowdhury et al., 2008; Koul et al., 2008). These antifungal compounds present in higher plants are the well-known factors to disease resistance. They are biodegradable and selective in toxicity.

Various compounds isolated from plants have been studied for insecticidal activity globally (Dev and Koul, 1997) and majority of them are insect antifeedants (Jermy, 1990; Koul, 2005). More than 140 compounds, which are chemically diverse and structurally complex, have been isolated from the leaves, seed oil and bark of neem (Koul, 2005). Phytochemicals are often distasteful and toxic to many pests. They can modify behaviour of an insect by acting directly on the chemosensilla resulting in feeding deterrence (Isman, 1994).

Jute (Corchorus olitorius L. and C. capsularis L.) is an important fibre crop next to cotton. It is mainly cultivated in India, Bangladesh, China, Nepal and Thailand. Its fibre is used for making bags, decoratives, textiles and geotextiles and its sticks are used for fuel, door panels of automobiles, and for making false ceiling boards. Its production and productivity is hampered by number of abiotic and biotic stresses. Among them stem rot, Macrophomina phaseolina (Tassi) Goid and Bihar hairy caterpillar, Spilosoma obliqua Walker (Arctiidae: Lepidoptera) are devastating and often causing yield losses. $M$. phaseolina causing stem rot in jute is the most economically important disease. Besides stem rot, the pathogen causes damping off, seedling blight, leaf blight, tip blight, collar rot and root rot (Roy et al., 2008). The disease is reported from all the jute growing countries affecting equally both the cultivated species of jute with $10.00 \%$ loss in fibre yield. Fibre yield loss reported even up to $35.00-40.00 \%$ under severe infection in hot $\left(34 \pm 1^{\circ} \mathrm{C}\right)$ and humid weather (Mandal, 1990).

The $S$. obliqua is a polyphagus pest attacking wide range of crops including bast fibre crops like jute and mesta. Previously it was considered as sporadic and irregular pest of jute in less rainfall areas and gradually 
this pest has turned to a major pest of jute in heavy rainfall areas like North Bengal and Assam (Das, 1948). In the present study, efforts were made to explore the naturally available various plant extracts as antifeedant against $S$. obliqua and antifungal agent against $M$. phaseolina affecting jute crop.

\section{MATERIALS AND METHODS}

Collection and preparation of plant extracts: Jute (C. capsularis), mesta (Hibiscus sabdarrifa), sunnhemp (Crotolaria juncia), C. quinquefolia, ramie (Bohemea nivea), sisal (Agave sisalana), curry leaf (Murraya koenigii), goat weed (Azeratum conyzoides) and marigold (Tagetis sp.) plants were grown at ICARCentral Research Institute for Jute and Allied Fibres research farm, Kolkata, West Bengal. Plant leaves were washed properly in cold water and dried under shade. Dried leaves were grinded in a mechanical grinder to fine powder. Leaf powder were put into different solvents (Hexane, Acetone, Methanol, Ethanol, Ethyl Acetate) and kept in room temperature for a week as per (Sindhan et al., 1999). Garlic cloves were peeled off and then macerated in a mortar and pestle to make it paste and then dipped into methanol for a week in room temperature. Solvent extracts were filtered through activated charcoal bed to remove pigments and then passed through sodium sulphate bed to remove moisture. The solvent was evaporated under vacuum to obtain concentrated plant extracts. Hexane extract of turmeric powder after evaporation of solvent yielded $3.45 \%$ oil (w/w). Other plant samples extracted in solvents when passed through charcoal bed and then through sodium sulphate bed clear and dry solvent extracts were obtained. Evaporation of solvents under vacuum yielded $4.5-16.6 \%(\mathrm{w} / \mathrm{w})$ concentrated extracts. Required quantities of the plant extracts were dissolved appropriate solvents to prepare test solutions (5,000 ppm and 2,000 ppm) for bioassay on the fungus and test insect i.e Bihar hairy caterpillar, Spilosoma obliqua.

Fungal bioassay: Effect of plant extracts $(5,000 \mathrm{ppm}$ and $2000 \mathrm{ppm}$ ) on radial growth and spore germination inhibition of $M$. phaseolina was studied up to seven days from inoculation by poisoned food technique using potato dextrose agar (PDA) medium (Nene and Thapliyal, 1979). For the mycellial growth inhibition studies, seven day old growth of M. phaseolina was used. The four replicated PDA Petriplates were inoculated with $5 \mathrm{~mm}$ disc of $M$. phaseolina at the center of each of the plates. Both treated and untreated (only solvent) Petriplates were incubated at $27 \pm 1^{0} \mathrm{C}$ inbiological oxygen demand (BOD) incubator and the mycelial growth of the fungus was measured diametrically in three different directions after 7 days and antagonistic potential of plant extracts was calculated as per the formula of $\mathrm{I}=\mathrm{C}-\mathrm{T} / \mathrm{C} * 100$, where $\mathrm{I}=$ inhibition in mycelial growth; $\mathrm{C}=$ growth of mycelium in control $(\mathrm{mm}) ; \mathrm{T}=$ growth of mycelium in treatment $(\mathrm{mm})$. The data obtained were analyzed following completely randomized design (CRD).

Seven day old culture of test fungus was taken from PDA slant and spore suspension was made by addition of sterilized distilled water taking small bit of fungal culture in $20 \mathrm{ml}$ of sterilized distilled water. Haemocytometer was used to get standardized spore suspension $\left(1 \times 10^{6}\right.$ spores $\left./ \mathrm{ml}\right)$. Small droplets $(0.02 \mathrm{ml})$ of the test solution and spore suspension in equal amount were seeded in the cavity slides. These slides were kept in Petriplates lined with moist filter paper and then incubated for $24 \mathrm{hrs}$ at $25 \pm 1^{\circ} \mathrm{C}$. Germination of the spores was recorded on 0-4 scale and per cent spore germination was calculated.

Bioassay against $S$. obliqua: The first instar larvae of $S$. obliqua were collected from the field and reared in the laboratory on jute leaves $(C$. olitorius) in glass jars $(20 \times 15 \mathrm{~cm})$ at $27 \pm 1^{0} \mathrm{C}$ and $70 \pm 5 \%$ relative humidity. After $24 \mathrm{hrs}$ of feeding, the larvae were transferred to fresh leaves in another disinfected container. Full grown and about to pupate larvae were transferred to glass jars having a thick layer of sterilized soil. The moths emerging after a week were collected and transferred to clean jars containing a suspended cotton swab soaked in honey solution and pieces of folded papers at the bottom for oviposition. The eggs laid were separated and observed for hatching every day. The freshly hatched larvae of the same batch were removed and kept separately on fresh and tender jute leaves in a glass jar in order to have $3^{\text {rd }}$ instar larvae of uniform weight (30-40 mg) were selected for bioassay of plant extracts for feeding inhibition activity and larval mortality of S. obliqua as per Chowdhury et al (2012b). Larval mortality after $24 \mathrm{hrs}$ of feeding was also counted and corrected larval mortality was calculated as per Abbott (1925). Corrected mortality $(\%)=(\mathrm{T}-\mathrm{C}) /$ $(100-\mathrm{C}) \times 100$ where, $\mathrm{T}=$ mortality in treatment and $\mathrm{C}=$ mortality in control. The per cent feeding inhibition and larval mortality (corrected) data were arcsine transformed.

Antifeedant activity against $S$. obliqua: Forced feeding method was followed for testing the antifeedant activity of the plant extracts on $3^{\text {rd }}$ instar larvae of S. obliqua (Abdelgaleil and Nakatani, 2003). Jute leaves of uniform size were plucked from insecticides free plots, washed thoroughly with distilled water and dried under shade. For each treatment five leaves were treated with the botanicals, air dried and placed inside the Petriplates $(15 \mathrm{~mm} \times 1.5 \mathrm{~mm})$ followed by ten $3^{\text {rd }}$ instar larvae of $S$. obliqua pre-starved for $6 \mathrm{hrs}$ were released and all treatments were replicated thrice. The outer margin of each leaf offered for feeding was traced in the graph paper. The extent of consumption of leaves after $24 \mathrm{hrs}$ was measured from the graph paper (Sarma and Kalita, 2001). Consumption data of solvent treated leaf disc was taken as control. Feeding inhibition (\%) was calculated as described by Pande and Shrivastav, 2003). Feeding inhibition $(\%)=(\mathrm{C}-\mathrm{T}) /$ $(\mathrm{C}+\mathrm{T}) \times 100$ where $\mathrm{C}=$ consumption of leaf in control and $\mathrm{T}=$ consumption of leaf in treatment. Larval mor- 
tality after $24 \mathrm{hrs}$ of feeding was also recorded.

\section{RESULTS AND DISCUSSION}

Effect of plant extracts on growth and spore germination on $M$. phaseolina: The mycellial growth of $M$. phaseolina was recorded in $2000 \mathrm{ppm}$ test solutions of marigold, goat weed, mesta, sunnhemp and sisal extracts treated petriplates at seven days after treatment. However, sunnhemp extracts (acetone, ethanol) along with the acetone extract of $A$. conyzoides, inhibited mycellial growth of the fungus by about 33.00$41.85 \%$ over control (Table 1). Previous study also revealed that the garlic extract inhibited maximum mycelial growth $(73.00 \%)$ as well as sclerotial formation followed by rhizome extract of turmeric (63.98\%) (Dhingani et al., 2013). The sporulation inhibition of M. phaseolima was recorded to be $66.67 \%$ and $83.32 \%$ in acetone extract of $A$. conyzoides and to be normal sunnhemp recorded $33.32 \%$ spore germination inhibition. Similar study was also carried out by Tandel et al. (2010) and results obtained were in confirmation of the present investigation and it was revealed that onion bulb extract resulted maximum inhibition $(98.14 \%)$ of M. phaseolina followed by extract of acacia, ginger, neem, garlic and karanji. Less than $10.00 \%$ sporulation inhibition was recorded by rest of the extracts. Present results are also in confirmation with those described earlier and who found the fungitoxic properties of Acacia arabica, Allium cepa, A. sativa against vegetative growth and sclerotial viability of $M$. phaseolina
(Dubey and Dwivedi, 1991).

At $5000 \mathrm{ppm}$, methanolic extract of curry leaf and turmeric oil recorded about $50.00 \%$ and $70.00 \%$ radial growth inhibition respectively, however, methanolic extract of $C$. quinquifolia and garlic recorded $35.55 \%$ and $44.44 \%$ radial growth inhibition of $M$. phaseolina, respectively. Similarly, Cowdhury et al. (2012a) studied the pathogenicity of turmeric oils against $M$. phaseolina and found bioactive turmerones in the oil. Methanolic extract of ramie leaf recorded less than $20 \%$ radial growth inhibition in the fungus (Table 2). The present study also supported by the previous workers that Crotalaria leaf extract are having fungicidal action (Rao, 1957; Vernier et al., 2005; Gomes et al., 2005). M. phaseolima sporulation inhibition $80.50 \%$ and $56.75 \%$ in hexane extract of turmeric and methanol extract of $C$. quinquifolia, respectively at $5000 \mathrm{ppm}$ was recorded. The acetone extract of $A$. conyzoides and alcoholic extract of sunnhemp was found to have inhibitory effect on mycelial growth of M. phaseolina and similar studies on plant extracts were reported by Appleton and Tansey (1975) who found the growth inhibitory effect of garlic extract on pathogenic fungi.

Effect of plant extracts on feeding inhibition and mortality of $S$. obliqua: In the present study, sunnhemp, $C$. quinquifolia, curry leaf, garlic extracts were also found active in causing feeding inhibition in $S$. obliqua and some of them caused larval mortality. Methanolic extracts (2000 ppm) of neem, sunnhemp,

Table 1. Effect of plant extracts on mycellial growth and sporulation of M. phaseolina at $2000 \mathrm{ppm}$.

\begin{tabular}{|c|c|c|c|c|}
\hline Plant extracts & $\begin{array}{l}\text { Mean radial } \\
\text { growth }(\mathrm{cm})\end{array}$ & $\begin{array}{c}\text { Growth inhibition over } \\
\text { control }(\%)\end{array}$ & $\begin{array}{l}\text { Mean sporulation } \\
\quad(0-4 \text { scale })\end{array}$ & $\begin{array}{c}\text { Spore germination } \\
\text { inhibition over control }(\%)\end{array}$ \\
\hline Jute (Ethyl acetate) & 8.90 & $0.74(4.93)^{*}$ & 3.67 & $8.25(16.69)$ \\
\hline Marigold (Acetone) & 9.00 & $0.00(0.00)$ & 3.67 & $8.25(16.69)$ \\
\hline A. conyzoides(Acetone) & 5.20 & $41.85(40.31)$ & 1.33 & $66.67(54.74)$ \\
\hline Mesta (Ethanol) & 9.00 & $0.00(0.00)$ & 3.67 & $8.25(16.69)$ \\
\hline Mesta (Acetone) & 9.00 & $0.00(0.00)$ & 3.67 & $8.25(16.66)$ \\
\hline Sunnhemp (Acetone) & 5.70 & $34.44(35.93)$ & 0.67 & $83.32(65.89)$ \\
\hline Sunnhemp (Ethanol) & 6.10 & $33.33(35.26)$ & 2.67 & $33.32(35.26)$ \\
\hline Sisal (Acetone) & 9.00 & $0.00(0.00)$ & 3.67 & $8.25(16.69$ \\
\hline Control (no spray) & 9.00 & $0.00(0.00)$ & 4.00 & $0.00(0.00)$ \\
\hline $\operatorname{LSD}(\mathrm{P}=0.05 \%)$ & 0.80 & -- & 1.52 & --. \\
\hline
\end{tabular}

*Figures in parenthesis are arc sine transformed values

Table 2: Effect of plant extracts on mycellial growth of M. phaseolina at $5000 \mathrm{ppm}$.

\begin{tabular}{ccccc}
\hline Plant extracts & $\begin{array}{c}\text { Mean radial } \\
\text { growth }(\mathbf{c m})\end{array}$ & $\begin{array}{c}\text { Growth inhibition over } \\
\text { control (\%) }\end{array}$ & $\begin{array}{c}\text { Mean sporulation } \\
\text { (0-4 scale) }\end{array}$ & $\begin{array}{c}\text { Spore germination inhibi- } \\
\text { tion over control (\%) }\end{array}$ \\
\hline Turmeric oil (Hexane) & 2.700 & $70.00(56.79)$ & 0.78 & $80.50(63.79)$ \\
Curry leaf (Methanol) & 4.50 & $50.00(45.00)$ & 2.37 & $40.75(39.67)$ \\
Ramie leaf (Methanol) & 7.50 & $16.66(24.09)$ & 3.79 & 2.82 \\
Garlic (Methanol) & 5.00 & $44.44(41.81)$ & 1.73 & $29.50(32.90)$ \\
C. quinquifolia (Methanol) & 5.80 & $35.55(36.60)$ & 4.00 & $56.75(48.88)$ \\
Control (no spray) & 9.00 & $00.00(0.00)$ & 0.48 & $0.00(0.00)$ \\
LSD (P=0.05\%) & 1.37 & - & -- \\
\hline
\end{tabular}

*Figures in parenthesis are arc sine transformed values 
Table 3: Effect of plant extracts on feeding of $3^{\text {rd }}$ instar larvae of Bihar hairy caterpillar at $2000 \mathrm{ppm}$.

\begin{tabular}{cccc}
\hline Plant extract & Leaf area fed /insect (\%) & Feeding inhibition (\%) & Larval mortality (\%) \\
\hline C. quinquifolia (Methanol) & $5.45(13.45)^{*}$ & $83.48(66.02)$ & $33.33(35.26)$ \\
C. juncea (Methanol) & $3.10(9.72)$ & $90.60(72.15)$ & $20.00(26.57)$ \\
Garlic (Methanol) & $2.00(8.13)$ & $93.94(75.75)$ & $44.44(41.81)$ \\
Curry leaf (Methanol) & $4.13(11.67)$ & $87.48(69.28)$ & $0.00(0.00)$ \\
Neem (Methanol) & $2.00(8.13)$ & $98.29(82.49)$ & $58.67(49.99)$ \\
Control (no spray) & $33.00(34.12)$ & $0.00(0.00)$ & $0.00(0.00)$ \\
LSD (P=0.05\%) & 14.21 & --- & - \\
\hline
\end{tabular}

garlic and curry leaf limited the leaf consumption by the starved $3^{\text {rd }}$ instar larvae of $S$. obliqua in comparison to the control (untreated). In previous studied the $S$. obliqua survivorship of larvae at 1000, 2000 and 3000 ppm of neem was significantly reduced to $51.00 \%$, $49.00 \%$ and $42.00 \%$ (Kapinder and Singh, 2014). In present study in control, $33.00 \%$ leaf area was consumed whereas in treated leaves only $2.00-5.45 \%$ leaf area was consumed by insect. Similarly, inhibitory activities of plant extracts have been screened against S. obliqua (Dubey et al., 2004). Thus above $98.00 \%$ feeding inhibition over control was recorded in all the plant extracts tested (Table 3). This feeding inhibition may be due to antifeedant activity possessed by plant extracts like neem oil (Mosaddaque, 1995). In a previous studies Adhatoda vasica caused the maximum mean mortality $(93.33 \%)$ which was significantly superior to Azadirachta indica>Curcuma domestica>Cleome monophylla>Alpinia galanga> the control against $S$. obliqua (Chandel et al., 2009).

In present studies, the larval mortality recorded $58.67 \%$ in neem extract treatment with $98.27 \%$ feeding inhibition. Though in control no insect mortality was observed, in case of garlic extract treated leaves the larval mortality was $44.44 \%$. C. juncea and C. quinquifolia extracts treated leaves recorded $20.00 \%$ and $33.33 \%$ larval mortality, respectively. No larval mortality in curry leaf extract was observed. Kumar and Ali (2010) observed that the standard check insecticide, endosulfan $35 \mathrm{EC}$ at $0.07 \%$ had the best performance, followed by $5 \%$ NSKE, $2 \%$ NLE, $0.15 \%$ nimbecidine, $2 \%$ neem oil, $2 \%$ mahuwa oil and 5\% KSKE, with $23.0,17.6,16.4,15.3,14.3$ and $11.5 \%$ larval population reduction, respectively against $S$. obliqua.

\section{Conclusion}

The methanolic extracts of $C$. juncea, $C$. quinquefolia, curry leaf and garlic showed upto $70 \%$ growth inhibition of $M$. phaseolina and $80.00 \%$ feeding inhibition of $S$. obliqua under in vitro condition. The methanolic plant extracts at 5000 ppm can be used effectively for the control of jute stem rot pathogen, M. phaseolina. Thus, the plant extract may have their greatest impact in future integrated pest management (IPM) programmes due to their safety to non-target organisms and the environment. Detailed investigation needs to be isolate the active constituents of the plant extracts responsible for the antifungal and insecticidal activities of the plant extracts which may lead to development of suitable botanical formulations that can be incorporated into the IPM programme for controlling the fungal disease and the insect pest in jute crop. The findings of this experiment may be helpful for management of $M$. phaseolina and S. obliqua.

\section{ACKNOWLEDGEMENTS}

The authors are grateful to the Director, ICAR-Central Research Institute for Jute and Allied Fibres, Barrackpore, Kolkata, for providing the necessary facilities for conducting the experiments.

\section{REFERENCES}

Abbott, W.S. (1925). A method for computing the effectiveness of an insecticide. Journal of Economic Entomology, 18: 265-267.

Abdelgaleil, S.A.M. and Nakatani M. (2003). Antifeeding activity of limonoids from Khaya enegalensis (Meliaceae). Journal of Applied Entomology, 127: 236239.

Appleton, J.A. and Tansey, M.R. (1975). Inhibition of growth of 200 pathogenic fungi by garlic extract. Mycologia, 67: 882-885.

Chandel, B.S., Vajpai, R.,Vajpai, S. and Rajni (2009) Bioefficacy of botanicals against Spilarctia obliqua. Annals of Plant Protection Sciences, 17 (2):465-466.

Chowdhury, H., Banerjee, T. and Walia, S. (2008).In vitro screening of Curcuma longa L. its derivatives as antifungal agents against Helminthosporium oryzae and Fusarium solani.Pesticides Research Journal, 20 (1): 69.

Chowdhury, H., Kar, C.S., Sarkar, S.K. and Tripathi, M.K. (2012b). Feeding inhibitory effect of some plant extracts on jute hairy caterpillar (Spilosoma obliqua).Indian Journal of Agricultural Sciences, 82 (1): 59-62.

Chowdhury, H., Walia, S. and Dhingra, S. (2012a). Bioefficacy of azadirachtin, turmeric oil and their mixture against Bihar hairy caterpillar (Spilosoma obliqua Walk.). Pesticide Research Journal,13(2): 165-172.

Das, G.M. (1948). Insect and mite pests of jute. Science\& Culture, 24: 186-190.

Dev, S. and Koul, O. (1997). Insecticides of Natural Origin. Harwood Academic Publishers, Amsterdam, the Netherlands. 357p.

Dhingani, J.C., Solankym, K.U. and Kansara, S.S. (2013). Management of root rot disease Macrophomina phaseo- 
lina (Tassi.) Goid of chickpea through botanicals and oil cakes.The Bioscan, 8(3): 739-742.

Dubey, R., Gupta, C. and Chandal, B.S. (2004). Efficacy of Acorus calamus, Vitex negundo and Ageratum conyzoides against Tobacco caterpillar, Spilarcta obliqua Walker. Indian Journal of Entomology, 66 (3): 238-240.

Dubey, R.C. and Dwivedi, R.S. (1991). Fungitoxic properties of some plant extract against vegetative growth and sclerotial viability $M$. phaseolina. Indian Phytopathology, 44: 411-413.

Gomes, C.E., Barbosa, A.E., Macedo, L.L., Pitanga, J.C., Moura, F.T., Oliveira, A.S., Moura, R.M., Queiroz, A.F., Macedo, F.P., Andrade, L.B., Vidal, M.S. and Sales, M.P. (2005). Effect of trypsin inhibitor from Crotalara pallida seeds on Callosobruchus maculatus (cowpea weevil) and Ceratitis capitata (fruit fly). Plant Physiology and Biochemistry, 43 (12): 1095-1102.

Isman, M.B. (1994). Botanical insecticides and antifeedants: New sources and perspectives. Pesticide Research Journal,6 (1): 11-19.

Isman, M.B. (2006). Botanical insecticides, deterrents and repellents in modern agriculture and an increasingly regulated world. Annual Review of Entomology,51:4566.

Jermy, T. (1990). Prospects of antifeedant approach to pest control - a critical review. Journal of Chemical Ecology, 16: 3151-3166.

Kapinder,T and Singh, A.K. (2014). Insecticidal and antifeedant activity of Melia azadarach (L.) fruits, on Spilosoma obliqua (Walker) (Lepidoptera: Arctiidae) larvae. Journal of Agricultural\& Veterinary Science, 7 (1):15-20.

Koul, O. (2005). Insect antifeedants. CRC Press, Boca Raton, FL.1005 p

Koul, O., Walia, S. and Dhaliwal, G.S. (2008). Essential oils as green pesticides: Potential and constraint. Biopesticide International, 4: 63-84.

Kumar, R. and Ali, S. (2010). Efficacy of botanical pesticides against Spilarctia obliqua in Sesamum indicum. Annals of Plant Protection Sciences, 18(1):223-224.

Mandal, R.K. (1990). Jute diseases and their control. In:
Proceedings of National Workshop cum Training on Jute, Mesta, Sunnhemp and Ramie. Central Research Institute for Jute and Allied Fibres, Barrack pore, West Bengal, India. Pp. 22-15.

Mosaddaque, M. (1995). Study on the use of neem oil alone and in combination with sesame oil to inhibit growth and development of jute hairy caterpillar, Spilosoma obliqua. Walker. M. Sc. Thesis, Department of Entomology, Bangladesh Agricultural University, Mymensingh. Pp.55-62.

Nene, Y.L. and Thapliyal, B.W. (1979). Fungicides in plant disease control. Oxford \& IBH Publisher house New Delhi. 425p.

Pande, D. and Srivastava, R. P. (2003). Toxicity and antifeedant activity of indoxacarb (Avaunt 14.5 SC) against tobacco caterpillar, Spodoptera litura (Fab.). Insect Environment, 9: 69-70.

Rao, S.D. (1957). The insecticidal property of petals of several plants of India. Economic Botany, 11 (3): 274-276.

Roy, A., De, R.K. and Ghosh, S.K. (2008). Diseases of bast fibre crops and their management in jute and allied fibres. Updates Production Technology, Central Research Institute for Jute and Allied Fibres, Barrckpore, West Bengal, India. 327p.

Sarma, M. and Kalita J. (2001). Assessment of foliage loss caused by different larval instars of Spilosoma obliqua on jute in Assam. Journal of Ecobiology, 13 (4): 313315.

Sindhan, G.S., Hooda, I. and Parashar, R.D. (1999). Effect of some plant extracts on vegetative growth of root rot causing fungi. Indian Journal of Mycology and Plant Pathology, 29: 110-11.

Tandel, D.H., Sabalpara, A.N. and Pandya, J.R. (2010). Efficacy of phytoextracts on Macrophomina Phaseolina (Tassi) Goid causing leaf blight of green gram. International Journal of Pharma and Biosciences, 2: 1-5.

Vernier, P., Goergen, G., Dossou, R.A., Letourmy, P. and Chaume, J. (2005). Utilization of biological insecticides for the protection of stored yam chips. Outlook Agriculture, 34 (3): 173-179. 